University of Nebraska - Lincoln

DigitalCommons@University of Nebraska - Lincoln

Sociology Department, Faculty Publications

Sociology, Department of

2011

\title{
Predictors of Change in Self-Reported Social Networks Among Homeless Young People
}

\author{
Christina D. Falci \\ University of Nebraska-Lincoln, cfalci2@unl.edu \\ Les B. Whitbeck \\ University of Nebraska-Lincoln, Iwhitbeck2@unl.edu \\ Dan R. Hoyt \\ University of Nebraska-Lincoln, dhoyt2@unl.edu \\ Trina Rose \\ University of Northern Colorado
}

Follow this and additional works at: https://digitalcommons.unl.edu/sociologyfacpub

Part of the Sociology Commons

Falci, Christina D.; Whitbeck, Les B.; Hoyt, Dan R.; and Rose, Trina, "Predictors of Change in Self-Reported Social Networks Among Homeless Young People" (2011). Sociology Department, Faculty Publications. 183.

https://digitalcommons.unl.edu/sociologyfacpub/183

This Article is brought to you for free and open access by the Sociology, Department of at DigitalCommons@University of Nebraska - Lincoln. It has been accepted for inclusion in Sociology Department, Faculty Publications by an authorized administrator of DigitalCommons@University of Nebraska - Lincoln. 
Published in Journal of Research on Adolescence 21 (2011), pp. 827-841; doi: 10.1111/j.1532-7795.2011.00741.x

Copyright (C) 2011 Christina D. Falci, Les B. Whitbeck, Dan R. Hoyt, \& Trina Rose.

Published for Society for Research on Adolescence by Wiley-Blackwell. Used by permission.

This research was supported by the National Institute of Mental Health (MH57110), Les B. Whitbeck, Principal Investigator.

\title{
Predictors of Change in Self-Reported Social Networks Among Homeless Young People
}

\author{
Christina D. Falci, Les B. Whitbeck, and Dan R. Hoyt \\ University of Nebraska-Lincoln \\ Trina Rose \\ University of Northern Colorado \\ Corresponding author - Christina Falci, Department of Sociology, University of Nebraska-Lincoln, \\ 711 Oldfather Hall, Lincoln, NE 68588-0324; email cfalci2@unl.edu
}

\begin{abstract}
This research investigates changes in social network size and composition of 351 homeless adolescents over 3 years. Findings show that network size decreases over time. Homeless youth with a conduct disorder begin street life with small networks that remain small over time. Caregiver abuse is associated with smaller emotional networks due to fewer home ties, especially to parents, and a more rapid loss of emotional home ties over time. Homeless youth with major depression start out with small networks, but are more likely to maintain network ties. Youth with substance abuse problems are more likely to maintain instrumental home ties. Finally, homeless adolescents tend to reconnect with their parents for instrumental aid and form romantic relationship that provide emotional support.
\end{abstract}

Adolescence is a time of rapid expansion and change in social networks. Not only are networks growing beyond primary family ties, they often are in flux as adolescents change school environments, reach out beyond their neighborhoods, join new groups, and engage in new activities (Cotterell, 2007). Negotiating this expansion of social ties, establishing one's place in them, and learning to garner social support from one's networks is a fundamental developmental task of adolescence (for a review see Parker, Rubin, Erath, Wojslawowicz, \& Buskirk, 2006). Becoming homeless disrupts young peoples' social networks by weakening ties to established networks at home, school, and the neighborhood and by rapidly introducing new network members during a time of high vulnerability and stress.

Even as the social networks of adolescents reconfigure, the size and composition of these networks continue to exert influence. As we learn more about the heterogeneity of the social networks of homeless young people it has become apparent that they have simultaneously opposing effects on behaviors and well-being (Ennett, Bailey, \& Federman, 1999). Deviant peer affiliations on the streets may provide training for minor criminal behaviors associated with the street economy (Hagen \& McCarthy, 1997). But social networks also may provide emotional support and protection (Ennett et al., 1999; Ennew, 1994), reduce stress and depressive symptoms (Bao, Whitbeck, \& Hoyt, 2000; Unger et al.,
1998), and expedite getting off the streets altogether (Rice, Milburn, \& Rotheram-Borus, 2007; Rice, Stein, \& Milburn, 2008). There are common themes emerging from research on the social networks of homeless young people suggesting that some components of their social networks may be protective and that if properly exploited could form the basis for innovative, peer-based interventions (Ennett et al., 1999; Johnson, Whitbeck, \& Hoyt, 2005; Rice et al., 2008; Unger et al., 1998). To develop such interventions, however, we need to know more about homeless adolescents' social networks, particularly how they change across time. In this paper, we use growth curve analyses to investigate factors that affect changes in self-reported network size and composition among homeless adolescents who were part of a 3-year longitudinal study in four Midwestern states. We differentiate between networks that provide emotional support, such as caring, affection, and approval, and those that provide instrumental or tangible support, such as money, food, or a place to stay. The compositional network characteristics we explore include home network ties (composed of family members, school friends, and friends from their old neighborhood) or street network ties (composed of network members met while on the streets or in shelters). We also explore the presence or absence of specific role relationships (e.g., parent, friend, or romantic partner) within a network. 


\section{THE SOCIAL NETWORKS OF HOMELESS YOUNG PEOPLE}

The social networks among homeless young people are smaller than those of housed young people (Van Der Ploeg, Gaemers, \& Hoogendam, 1991). Ennett et al. (1999) reported that the networks of homeless adolescents were very small, on average less than three relationships compared with $15-17$ relationships among teens in the general population. There are good reasons for smaller networks. Adolescent social networks can be highly sensitive to change and those made up of nonconventional peers even more so. For example, the size, composition, and stability of adolescent social networks are particularly susceptible to mobility.

Adolescents who change schools or residence have fewer friends, are less popular, and have friends who are less popular than adolescents who have been residentially stable. The effects of mobility may persist for several years (South \& Haynie, 2004). Homeless adolescents are probably the most mobile of all young people. They live a revolving-door lifestyle moving from doubling-up to the streets, to group homes and foster care to home and then back to the streets (Whitbeck \& Hoyt, 1999). Each move may involve being out of school, moving to a different school or alternative school setting. Thus, homeless youth are likely to start out with small networks and the size of their networks might decline over time.

The most unstable person in a homeless adolescent's network may be a network member that the adolescent met on the street. Whitbeck (2009) reported median network turnover rates of $50 \%-60 \%$ over 3 years among homeless young people. Turnover was higher among homeless youth with a higher proportion of street associates. In contrast, safer and more stable relationships may be found in ties to the old neighborhood or home. Past research has demonstrated that many homeless young people maintain ties to family and housed friends. Rice et al. (2007) reported the majority of newly homeless young people still had ties to family and to housed friends who were attending school. We expect that homeless youth will report a higher number of network ties to their home environments than to their street associates.

\section{CAREGIVER ABUSE AND MENTAL HEALTH}

Instability in homeless youth networks is not solely a function of residential mobility or unstable street associations. Forming and maintaining social relationships depends on a skill set that involves the interest in and ability to share, empathize with others, recognize social cues, trust and disclose to others, and to be loyal across time (for reviews see Berndt \& Hanna, 1995; Buhrmester \& Prager, 1995; Newcomb \& Bagwell, 1995). For a variety of reasons, this skill set may be compromised among homeless youth. Homeless young people are highly likely to have left disorganized and coercive/aggressive families (Whitbeck \& Hoyt, 1999). Children growing up in such families learn interaction styles characterized by power assertion and the expectation of conflict with others (Du Rocher Shudlilch, Shamir, \& Cummings, 2004; Patterson, 1982; Wilson \& Gottman, 2002). These disadvantaged backgrounds often lead to behavioral problems that further compromise their ability to develop and maintain social connections while homeless. A high proportion of homeless adolescents meet diagnostic criteria for one or more psychiatric disorders, particularly conduct disorder, substance abuse disorder, and major depressive disorder (Whitbeck, 2009; Whitbeck, Johnson, Hoyt, \& Cauce, 2004).

\section{Caregiver Abuse}

We know that homeless youth tend to maintain ties to family members from back home, but these ties are more common among homeless youth who have better relationships with family members and lower rates of physical and sexual abuse by adult caretakers (Johnson et al., 2005; Tavecchio \& Thomeer, 1999; Whitbeck \& Hoyt, 1999). Homeless youth who come from the most hostile home environments may be less likely to rely on family members for emotional or instrumental support. This could result in smaller-sized networks overall if they are unable to make up those "lost" home ties with ties formed on the street. Thus, we expect adolescents with a history of caregiver abuse to have smaller networks due to fewer connections to their home environment compared with adolescents without a history of caregiver abuse. Over time, we also expect that adolescents might be less inclined to turn toward potentially abusive or rejecting family members for emotional and instrumental support even if they do not get enough such support from their street connections. Thus, adolescents with a history of caregiver abuse may experience steeper declines in their home networks compared with adolescents without a history of caregiver abuse.

\section{Conduct Disorder}

Adolescents who meet diagnostic criteria for conduct disorder are especially apt to be disliked by peers and 
to have problematic social relationships primarily because they tend to be more aggressive, intimidating, and insensitive to the rights of others (for a review see Hinshaw \& Lee, 2003). For these reasons, we expect adolescents who meet criteria for conduct disorder will have smaller social networks than adolescents without a history of conduct disorder. Over time, these same factors should be associated with a decline in network size. In other words, adolescents who meet the criteria for conduct disorder will have steeper declines in network size compared with adolescents without a conduct disorder. We expect these declines to be constant across the compositional characteristics of networks.

\section{Substance Abuse}

Youth who meet criteria for substance abuse disorder are likely to have low-quality, conflicted, often mutually exploitive social relationships surrounding episodes of substance use, procuring or dealing substances, and the behaviors associated with addiction (McCrady, 2006). Therefore, we expect adolescents who meet the criteria for substance abuse to have smaller networks compared with adolescents without a substance abuse disorder. Their networks are also likely to become increasingly smaller over time, especially to street associates. Youth with a substance abuse problem need instrumental resources to sustain their habit, which may be more abundant in their home rather than street environments. For example, they may have established connections for procuring addictive substances within their home environments. As a result, homeless young people with a substance abuse disorder may be more likely to maintain the size of their instrumental home networks over time.

\section{Major Depression}

Research also indicates that depressed young people have difficulty establishing relationships with peers. Depressed children view themselves as less accepted by their peers that nondepressed children (Brendgen, Vitaro, Turgeon, \& Poulin, 2002) and depressed youth may also be more likely to isolate themselves from others (Link, Cullen, Struening, Shrout, \& Dohrenwend, 1989). These qualities are likely to lead to smaller-sized networks compared with nondepressed young people. At the same time, among homeless youth, peers who are depressed may seem like better friend choices compared with peers with conduct disorders or substance abuse problems who tend to be aggressive, hostile, or manipulative. In other words, depressed homeless youth may appear more worthy of empathy and support than homeless youth who suffer from different mental health problems. For these reasons, depressed young people may be better able to maintain their network connections over time, especially connections formed on the street, once a connection is formed compared with homeless adolescents who are not depressed.

\section{THE CURRENT STUDY}

The current research has three aims. First, we illuminate how the initial size and growth of homeless emotional and instrumental self-reported networks vary across caregiver abuse and mental health outcomes. Second, we further assess if these general patterns in self-reported network size vary depending on the origin of the tie (street vs. home). Finally, we explore the presence or absence of specific role relationships (e.g., parent or romantic partner) within the networks of homeless young people and variation therein across caregiver abuse and mental health outcomes.

\section{METHOD}

\section{Sample}

The Midwest Longitudinal Study of Homeless Adolescents is a longitudinal sample of 369 homeless and runaway youth living independently on the street or in shelters. Face-to-face interviews were conducted by fulltime specially trained street interviewers. The study began in 2000 when youth were between the ages of 16 and 19 years. To generate a diverse sample of youth (Burt, 1996; Dennis, Iachan, Thornberry, \& Bray, 1991; Iachan, 1989; Koegel, Burnam, \& Morton, 1996), interviewers repeatedly checked fixed locations (such as shelters) and street "spots" (e.g., common hangouts) within seven cities in four Midwestern states (Missouri, Iowa, Nebraska, and Kansas). Interviewers also varied the times of day for visiting these settings and worked on weekdays and weekends. Recruitment into the study occurred over a one-year time frame capturing both long-term and short-term homeless youth (Phelan \& Link, 1999).

Informed consent was obtained from the adolescent respondent. Respondents were assured that refusing to participate in the study, refusing to answer a specific question, or stopping the interview process would have no effect on current or future services provided by the outreach agency in which the interviewer was placed. Adolescents under the age of 18 were asked if their par- 
ents could be contacted. If permission was granted, parents were contacted, and informed consent to talk to a minor under 18 years was verbally obtained. If the adolescent was sheltered, we followed shelter policies of parental permission for placement and guidelines concerning granting such permissions. These policies were always based on state laws. In the few cases where the adolescent was under 18 years, not sheltered, and refused permission to contact parents, the adolescents were treated as emancipated minors in accord with $\mathrm{Na}$ tional Institute of Health guidelines (Department of Health and Human Services, 2001). The consent process and questionnaires were approved by the University of Nebraska-Lincoln Institutional Review Board (\#200107-333 FB). A National Institute of Mental Health Certificate of Confidentiality was obtained to protect the respondent's statements regarding potentially illegal activities (e.g., drug use).

Once recruited, the young people were tracked for a total of 3 years and interviewed every 3 months - producing 13 possible waves of data. The interviewers attempted to track respondents wherever they went including home, jail, group homes, etc. The analytic sample for the study is 351 homeless young people. Eighteen cases are lost due to missing data on sexual orientation and street exposure in the first wave of the study. Almost $25 \%$ of respondents have 12 or 13 waves of data. On average, each respondent has slightly over seven waves of data, and $75 \%$ of respondent have three or more waves of data. Sixteen percent of respondents have only one wave of data, but the hierarchical generalized linear modeling techniques used in data analysis allows us to keep all 351 respondents in the sample. The descriptive statistics for wave one measures are provided in Table 1.

\section{Measures}

Social network characteristics. All network characteristics were measured at each wave of data collection and are based on the respondent's report of their network size. Youth's total network size was measured for two types of relational tie content: instrumental aid and emotional support. To assess the number of instrumental support ties, respondents were asked: "Are there people in your life you can count on to give you help and aid? People who may lend you money, give you food, or give you a place to stay without asking for anything in return?" To assess the number of emotional support ties, respondents were asked: "Are there people in your life you can count on to care about you, no matter what is happening to you? People that accept you totally, including your good and bad points, people
Table 1. Descriptive Statistics for Wave 1

\begin{tabular}{|c|c|c|c|c|}
\hline & Mean & SD & Min & Max \\
\hline \multicolumn{5}{|l|}{ Dependent variables } \\
\hline \multicolumn{5}{|l|}{ Emotional network structure } \\
\hline \multicolumn{5}{|l|}{ Network size } \\
\hline Total & 4.41 & 4.91 & 0 & 19 \\
\hline Core & 2.13 & 1.10 & 0 & 3 \\
\hline Isolate & 0.14 & 0.34 & 0 & 1 \\
\hline \multicolumn{5}{|l|}{ Relationship origin } \\
\hline Street network size & 0.59 & 0.88 & 0 & 3 \\
\hline Home network size & 1.54 & 1.18 & 0 & 3 \\
\hline \multicolumn{5}{|l|}{ Relationship type } \\
\hline Parent & 0.30 & 0.46 & 0 & 1 \\
\hline Other family member & 0.38 & 0.49 & 0 & 1 \\
\hline Significant other & 0.19 & 0.39 & 0 & 1 \\
\hline Friend & 0.51 & 0.50 & 0 & 1 \\
\hline \multicolumn{5}{|c|}{ Instrumental network structure } \\
\hline \multicolumn{5}{|l|}{ Network size } \\
\hline Total & 3.80 & 4.43 & 0 & 19 \\
\hline Core & 1.94 & 1.20 & 0 & 3 \\
\hline Isolate & 0.21 & 0.40 & 0 & 1 \\
\hline \multicolumn{5}{|l|}{ Relationship origin } \\
\hline Street network size & 0.61 & 0.89 & 0 & 3 \\
\hline Home network size & 1.33 & 1.20 & 0 & 3 \\
\hline \multicolumn{5}{|l|}{ Relationship type } \\
\hline Parent & 0.12 & 0.32 & 0 & 1 \\
\hline Other family member & 0.29 & 0.46 & 0 & 1 \\
\hline Significant other & 0.14 & 0.35 & 0 & 1 \\
\hline Friend & 0.62 & 0.48 & 0 & 1 \\
\hline \multicolumn{5}{|l|}{ Independent variables } \\
\hline Caregiver abuse & 0.03 & 0.67 & -1 & 1 \\
\hline Major depression & 0.32 & 0.47 & 0 & 1 \\
\hline Conduct disorder & 0.76 & 0.43 & 0 & 1 \\
\hline Substance use & 0.63 & 0.48 & 0 & 1 \\
\hline Street exposure (in months) & 16.44 & 12.83 & 0 & 48 \\
\hline \multicolumn{5}{|l|}{ Demographics } \\
\hline Age & 17.45 & 1.04 & 16 & 19 \\
\hline Female & 0.55 & 0.50 & 0 & 1 \\
\hline Heterosexual & 0.84 & 0.37 & 0 & 1 \\
\hline
\end{tabular}

$N=351$

who are ready to accept you when you are upset, and who are really concerned about your feelings and welfare?" A "no" response to these questions was coded as a " 0 " for total network size and the youth was considered an isolate for the relational tie. A "yes" response to the above questions was followed up with the following question: "How many people like that do you have in your life?" The range for total emotional network size was $0-19$ and the range for total instrumental network size also was $0-19$.

To identify an adolescent's core network respondents were next asked: "Thinking of these people who 
would you go to first for help or aid?" after the instrumental ties query, and asked: "Thinking of these people who would be the first person you would say is the most accepting and concerned about you?" after the emotional ties query. Subsequent questions asked: “... who would you go to next for ..." Respondents were allowed to name up to three people in their core networks; thus, the size of core instrumental and emotional networks ranged from 0 to 3 . For the majority of respondents, the core network size reported in Wave 1 was equivalent to their total network size reported in Wave 1 (66\% for instrumental networks and 59\% for emotional network). Thus, the core network size is a good approximation of total network size. In addition to measures of network size, we created a measure of network isolation. We created a dichotomous measure to distinguish adolescents who reported they had no one to count on for emotional support $(\operatorname{code}=1)$ from adolescents who reported they had one or more people to count on for emotional support ( $\operatorname{code}=0$ ). An analogous measure of network isolation was also created for instrumental networks.

Once adolescents identified their core network members (i.e., the three primary members of their total network), additional questions were asked about each member of the adolescent's core network. First, to ascertain whether the relationship started from a street or home connection respondents were asked: "Do you know this person mostly from being on the street, or mostly from back home?" The relationship origin street network size indicates the number of individuals nominated from the street and the relationship origin home network size indicates the number of individual nominated from home. Like core network size, the range for these measures was from 0 to 3 . These measures were created for both emotional and instrumental networks. Second, to establish the role relationship of the network tie respondents were asked: "What is your relationship to this person?" Open-ended responses were coded into one of four categories: a parent, family other than parent (extended family or siblings), friend, and romantic partner. A series of dichotomous measures were created indicating whether or not a specific type of role relationships was reported by the adolescent for each core network (emotional and instrumental) across all waves of data collection. For example, if an adolescent reported a parent as part of their emotional network, then the relationship type parent variable would be given the value of " 1 " and " 0 " if no parent was mentioned in the core emotional network.
Independent variables. In the first wave, respondents were administered the Diagnostic Interview Schedule for Children-Revised Version II (DISC-R) by trained interviewers to assess conduct disorder, substance abuse disorders, and major depressive episode (American Psychiatric Association, 2000). The DISC-R is considered to be a state-of-the-science structured interview to assess behavioral disorders in children and adolescents (Schwab-Stone et al., 1993; Shaffer et al., 1993; Weinstein, Noam, Grimes, Stone, \& Schwab-Stone, 1990). The DISC-R has good to excellent interrater and test - retest reliability (Jensen et al., 1995; Shaffer et al., 1993). The focal independent variables developed from the DISC$\mathrm{R}$ are based on check-lists of diagnostic criteria and produce dichotomous indicators where a value of 1 indicates meeting the lifetime prevalence diagnostic criteria for alcohol substance abuse, major depression disorder, and conduct disorder. The majority of homeless youth at some point before the first wave of data collection have met the criteria for conduct disorder $(76 \%)$ and substance abuse $(63 \%)$, and many have suffered from major depression (32\%).

Caregiver abuse is a 14-item scale (Cronbach's $\alpha=$ .90) with questions pertaining to emotional, physical, and sexual abuse. Adolescents were asked "How often has any adult who was taking care of you ever: given you angry stares or looks; ignored you didn't pay any attention to you or pretended you weren't there; hurtful or insulting things to you; called you names or criticized you; told you that you were a bad person; threatened to abandon you; made you feel that you were unimportant or not special; thrown something at you in anger; pushed shoved, or grabbed you in anger; slapped you in face or head with an open hand; hit you with some object; ever beat you up with their fists; ever made you do something sexual or messed around with you sexually." The set of response choices for these questions were either never, seldom, sometimes, often and always, or the response choices were never, once, two to five times, and more than five times. Therefore, items were standardized before scale construction.

Control variables. In all multivariate analyses, we control for age, gender, and sexual orientation of the respondent as these demographic characteristics are likely to be linked to size and compositions of networks (Cochran, Stewart, Ginzler, \& Cauce, 2002; Johnson et al., 2005; Rice et al., 2008; Whitbeck, Chen, Hoyt, Tyler, \& Johnson, 2004). Interviewers reported on whether the respondent was male (0) or female (1). Participants were asked: "how would you describe your 
sexual orientation?" and the response choices were: straight or heterosexual, gay/lesbian, bisexual, never thought about it, something else, and confused/unsure. If respondents reported being straight or heterosexual, they were given the value of one for the variable heterosexual and zero for any other responses. Eightyfour percent of the sample identified as heterosexual. Fifty-five percent of the sample is female. Based on the month and year of the respondents' date of birth and the month and year that each interview occurred, age at the time of interview was computed in months (the value is converted to years within all statistical analyses). Thus, we have a measure of age at every wave of data collection. The average age in Wave 1 was 17.5 years.

Street exposure. Street exposure is measured using several different questions in the survey. In the first wave of the study, respondents were asked how old they were the most recent time they left home (or were kicked out). Subtracting this number from the respondents' age at time of the first interview provided an estimate of how long the respondent had been on the street before the Wave 1 interview. The mean length of time on the street in wave one was 16 months. To calculate street exposure in subsequent waves, first, the current age of the respondent was subtracted from the age of the respondent in Wave 1. This number identified the number of months between the first interview and the interview in the subsequent wave. Then, this number was added to the Wave 1 street exposure measure. For example, street exposure in Wave 2 was calculated by first subtracting the respondent's age in Wave 2 from the respondent's age in Wave 1. Finally, this number was added to street exposure in Wave 1.

This calculation strategy for street exposure allowed us to get an accurate count of the number of months on the street at each wave (even when respondents had missing waves of data and if there was variability in the time interval between waves across respondents). Consistent with study design, the average length of time between interviews was 3.24 months. Finally, as described earlier, homeless youth often live a revolving-door existence (staying in different places and drifting in and out of their home environments) and the interviewers attempted to track respondents wherever they went. Therefore, our measure of street exposure does not represent continuous time on the street for all respondents. Rather, the measure of street exposure approximates when the revolving-door homeless lifestyle began for all respondents.

\section{Data Analysis}

In the first phase of the analysis (Table 1), univariate statistics are provided for network size, mental health, and demographic characteristics of the sample. The size of instrumental and emotional networks is also broken down by the origin of the relational tie (home vs. street). To explore differences in the total size of emotional and instrumental networks or differences in the size of street and home networks we report the results of paired $t$-tests of means (using proc $t$-test in SAS with the paired statement) within the text of the findings section. We also explore the presence or absence of particular role relationships (e.g., parent) within emotional and instrumental networks. To test the equality of proportions across emotional and instrumental networks we report the results of Wilcoxon's signed rank sum tests (using the proc univariate procedure in SAS) within the text of the findings section.

In the second phase of analysis, we use hierarchical generalized linear growth curve models to explore how network size and composition changes the longer an adolescent remained homeless. Growth curve models utilize a hierarchical design where multiple observations for each individual are nested within a person (Raudenbush \& Bryk, 2002). All multivariate models in Tables 2,3 , and 4 are estimated using HLM 6 software with street exposure as the time variable and all the predictor variables are grand mean centered. Using street exposure as the time variable does lead to risk of extrapolating beyond our data. Across the 13 waves of data, the actual street exposure time span covered ranged from 1 month to 82 months; although $95 \%$ of the street exposure measurements across all waves fell below 60 months (5 years). Nevertheless, the authors feel that having a meaningful intercept outweighs the concerns with extrapolation.

In the hierarchical generalized linear models, the intercept is a random effect, but the growth rate is fixed by the link function. As such, we focus our interpretation on the fixed effects for all models. For comparability across models, the tables report standardized coefficients from population-average probabilities and significance based on robust standard errors. We do not report the deviance statistic because we are not comparing across nested models and such a comparison would be inappropriate for our model estimation (Snijders \& Bosker, 1999). The estimation procedures vary slightly depending on the outcome measure. For the count data (network size), we specify a log link function with an overdispersed Poisson's error distribution (Hox, 2002). 
The tables report standardized coefficients in the form of an event rate ratio (ERR), which are exponentiated coefficients. An ERR represents the percentage change in a dependent variable associated with a one unit increase in an independent variable, holding other factors constant. We used the unstandardized coefficients to calculate the predicted size of networks, mentioned in the findings section, by taking the inverse of the log $[\exp (Y)]$. For the dichotomous data (e.g., isolation), we specify a logit link function with a Bernoulli error distribution. The tables report odds ratios (OR), but we used the unstandardized coefficients to calculate predicted probabilities by applying the following formula: $1 /(1+\exp (-Y))$.

\section{RESULTS}

\section{Baseline Characteristics}

In the first wave of the study, homeless youth, on average, nominated 4.41 total individuals who were accepting or concerned about them (i.e., emotional ties) and 3.80 individuals who provided aid or help (i.e., instrumental ties) (see Table 1). Results of a paired $t$-test analysis confirm that emotional networks tend to be significantly larger than instrumental networks $(t=2.35, p=$ .019) among homeless youth. The same patterns occurred for core network size, in which respondents were only allowed to nominate up to three people. The average size of core networks was 2.13 for emotional ties and 1.94 for instrumental ties $(t=3.24, p=.001)$. Consistent with the results of network size, isolation was higher within instrumental compared with emotional networks. Fourteen percent of homeless youth reported that no one was accepting or concerned about them, whereas $21 \%$ of homeless youth indicated that they had no one to turn to for help or aid. The results of the Wilcoxon signed rank sum tests indicates the proportions are significantly different from one another $(s=303, p=$ .0007).

For core network members, additional information was collected about the nominated individuals allowing us to explore differences in relationship origin (street or home) and relationship type (parent, other family, friend, or significant other). Homeless youth reported more ties to people they knew from home in their core networks (1.54 on average) compared with people they knew from the street (less than one on average, .59) for emotional networks $(t=10.14, p<.001)$. The same trend was found for instrumental networks (an average of 1.33 ties from home and less than one from the street $.61 ; t$ $=7.87, p<.001)$. Thus, homeless youth have more primary emotional and instrumental network connections to their home environments.

Ties to the home environment, however, are not necessarily ties to parents. Adolescents were less likely to report having a parent $(30 \%)$ in their emotional network than having some other family member $(38 \%$; $s$ $=903, p=.013$ ). The differences are even larger within instrumental networks (12\% compared with $29 \%$; $s=$ $1494, p<.0001)$. Adolescents were also more likely to report having a friend in their emotional $(51 \%$; $s=3829$, $p<.0001)$ and instrumental $(62 \% ; s=9735, p<.0001)$ networks than a parent. In contrast, it was less common to have a significant other (19\%) within one's emotional network than to have a parent (30\%; $s=1221, p=.001)$. The proportion for having a parent $(12 \%)$ in one's instrumental network compared with a significant other (14\%) did not significantly differ $(s=193, p=.332)$.

\section{Size of Total and Core Networks}

Who is likely to have smaller social networks when first on the street? In the beginning of life on the street, adolescents with a history of conduct disorder had smaller total emotional $(\mathrm{ERR}=0.755, p<.05)$ and instrumental (ERR $=0.732, p<.05)$ networks (see Table 2 ). For example, the predicted size of an instrumental network for an adolescent with a conduct disorder is about four members (3.9) whereas adolescents without a history of conduct disorder have over five members (5.3) in their instrumental networks. The analogous numbers for emotional networks are 4.9 and 6.5, respectively. Adolescents with major depression also had smaller total emotional (ERR $=0.795, p<.05)$ and instrumental networks (ERR $=0.799, p<.05)$. For example, youth with depression have 3.6 people in their total instrumental network at the beginning of the study compared with 4.5 for youth who do not suffer from depression. Thus, on average, youth with a conduct disorder or depression reported one fewer total network members in their networks (emotional or instrumental) when they start their life on the street than youth without these mental disorders.

Variability in initial network size is also explained by caregiver abuse and age. Adolescents who experience more caregiver abuse have smaller total (ERR = $0.846, p<.05)$ and core (ERR $=0.907, p<.05)$ emotional networks and a higher probability of being an isolate $(\mathrm{OR}=1.746, p<.05)$ in their emotional networks compared with adolescents with lower levels of caregiver 
Table 2. Growth Curve Models for Emotional and Instrumental Network Size (N = 351)a

\begin{tabular}{|c|c|c|c|c|c|c|}
\hline & \multicolumn{6}{|c|}{ Network Size } \\
\hline & Total $^{b}$ & Core $^{b}$ & Isolate $^{\mathrm{C}}$ & Total $^{b}$ & Core $^{b}$ & Isolate $^{\mathrm{C}}$ \\
\hline Fixed effects & ERR & ERR & OR & ERR & ERR & OR \\
\hline Initial status & 5.326 & 2.308 & 0.123 & 4.244 & 2.137 & 0.214 \\
\hline Age & 0.985 & 1.010 & 0.810 & $0.800^{* * *}$ & $0.895^{* *}$ & 1.224 \\
\hline Heterosexual & 0.918 & $0.882^{*}$ & 1.279 & 0.935 & 0.948 & 0.953 \\
\hline Caregiver abuse & $0.846^{*}$ & $0.907^{*}$ & $1.746^{*}$ & 0.933 & 0.930 & 1.416 \\
\hline Major depression & $0.795^{*}$ & 0.921 & 1.041 & $0.799^{*}$ & 0.884 & 1.237 \\
\hline Conduct disorder & $0.755^{*}$ & 0.941 & 1.678 & $0.732^{*}$ & 0.970 & 1.747 \\
\hline Substance abuse & 1.111 & 0.984 & 0.938 & 1.235 & 0.971 & 0.903 \\
\hline Growth rate & $0.987^{* * *}$ & $0.995^{* * *}$ & $1.010^{* *}$ & $0.984^{* * *}$ & $0.993^{* * *}$ & $1.010^{* *}$ \\
\hline Caregiver abuse & 1.001 & 0.999 & 0.999 & 0.998 & 0.998 & 0.999 \\
\hline Major depression & $1.006^{*}$ & $1.005^{* *}$ & 0.990 & $1.009^{* *}$ & $1.006^{* *}$ & $0.985^{*}$ \\
\hline Conduct disorder & 1.002 & 0.998 & 1.015 & $1.008^{*}$ & 0.998 & 1.001 \\
\hline Substance abuse & 0.999 & 1.002 & 0.996 & 0.995 & 1.003 & 0.994 \\
\hline Random effects & $\mathrm{VC}$ & $\mathrm{VC}$ & $\mathrm{VC}$ & $\mathrm{VC}$ & $\mathrm{VC}$ & $\mathrm{VC}$ \\
\hline Initial status & $0.427^{* * *}$ & $.813^{* * *}$ & $2.937^{* * *}$ & $0.434^{* * *}$ & $.313^{* * *}$ & $2.284^{* * *}$ \\
\hline Level-1 error & 2.136 & .772 & & 1.852 & .570 & \\
\hline
\end{tabular}

$\mathrm{OR}=$ odds ratios; $\mathrm{ERR}=$ event rate ratio; $\mathrm{VC}=$ variance component.

${ }^{*} p<.05 ;{ }^{* *} p<.01 ;{ }^{* * *} p<.001$ (one-tailed test).

a. All variables are grand mean centered.

b. Overdispersed Poisson's model estimation for count variables total network size and core network size.

c. Bernoulli's model estimation for binary variable for Network Isolates.

abuse. Interestingly, these differences are limited to emotional networks. The size of instrumental networks did not vary by caregiver abuse. The opposite trend is found for age. Age predicts the size of instrumental total $(E R R=0.800, p<.001)$ and core $(E R R=0.895, p<.01)$ networks but not the size of emotional networks. It appears as though homeless youth who experience more caregiver abuse have a difficult time establishing emotional connections when they first become homeless compared with homeless youth with less caregiver abuse, whereas younger homeless adolescents more quickly find sources of instrumental aid compared with older homeless adolescents.

Does network size decline over time? The growth rates reported in Table 2 indicate that, on average, the size of emotional and instrumental networks declined the longer the adolescent remained on the street for both core and total networks. Figure 1 graphs the actual means (i.e., not the predicted means based on model coefficients) of total emotional and instrumental network size by time on street. The actual means indicate that, during their first 6 months of being homeless, youth on average had almost five (4.8) members in their emotional networks and four (4.1) in their instrumental networks. After the 2-year mark (between 25 and 30 months), homeless youth on

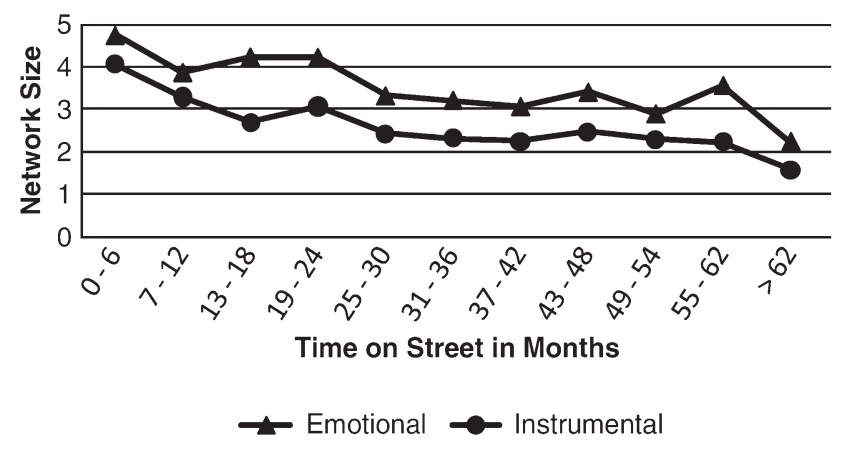

Figure 1. Changes in total network size. 
average had about three (3.3) members in their emotional networks and two (2.4) members in their instrumental networks. After 5 or more years (equal to or greater than 62 months) of being homeless, youth report having around two (2.2) members in their emotional network and less than two (1.6) members in their instrumental network.

We conducted two sensitivity analyses to explore the robustness of the growth curves reported above. First, we tested the possibility of nonlinear time effects by including squared terms for street exposure in our models. These higher order terms can identify if changes in network size over time take a nonlinear form, such as a curvilinear shape (e.g., initial declines followed by gains in network size). This trend, however, does not manifest in Figure 1, and the squared terms in the models were not statistically significant. Second, to assess a possible conflation of the effect of street exposure on network size with the influence of age, we conducted additional subgroup analyses (not shown). Eight subgroups were created based on the respondents age at Wave $1(16,17$, 18 , or 19) and the degree of street exposure in Wave 1 ( $<1$ year or 1-2 years). The results of these analyses showed growth rates of declining network size for each subgroup at very similar rates. Essentially, network size declines the longer an adolescent remained homeless regardless of how old they were at the first wave of data collection or how long they had been on the street before the first wave.

Consistent with the declines in network size, the odds of becoming an isolate within emotional $(\mathrm{OR}=$ $1.010, p<.01)$ and instrumental $(\mathrm{OR}=1.010, p<.01)$ networks increase the longer homeless youth remain on the street. During their first 6 months of being homeless, $12 \%$ of homeless youth had no one to go to for emotional support. After the 2-year mark, this number increases to $17 \%$ and to $20 \%$ after 5 years of being homeless. The numbers are even more disheartening in terms of instrumental aid. During their first 6 months of being homeless, $18 \%$ of homeless youth had no one to count on for instrumental support. After the 2-year mark, this number increases to $23 \%$ and to $31 \%$ after 5 years of being homeless. Clearly, the risk of isolation grows and the size of networks shrink the longer homeless youth remain on the street.

Who is more likely to lose network members over time? The lower half of Table 2 shows a clear pattern of major depression predicting the growth in network size. Homeless youth with major depression experienced less steep declines in the size of their total and core emotional or instrumental networks. Although the effect sizes for these changes do not appear to be very large (ranging from 1.005 to 1.009), it is important to keep in mind that the difference represents monthly change over a period of 3 years. Thus, small differences in the growth rate can accumulate into substantively meaningful differences in network size over time. For example, over a 3-year period homelessness youth who do not suffer from major depression lose an average of 2.2 members from their total instrumental network, whereas depressed homeless youth lose an average of 1.1. In other words, over a 3-year period depressed homeless youth are more likely to maintain about one additional person in their instrumental networks compared with homeless youth who do not suffer from major depression.

\section{Street and Home Networks}

This next phase of analysis separates the general trends reported above out by the origin of the network tie (see Table 3). Specifically, for each type of relational tie (emotional and instrumental) two separate hierarchical generalized linear regression models are run: one with the number of street ties as the outcome variable and one with the number of home ties as the outcome variable. This allows us to explore what predicts the initial size of home versus street networks, whether homeless youth are more likely to lose network ties to home versus street connections, and what predicts change in the size of home versus street networks. Because the questions about origin of the tie are only asked about members of the respondents' core networks, this analysis is restricted to investigating core network size.

What predicts differences in the size of home versus street networks when first on the street? The top half of Table 3 shows a clear pattern of caregiver abuse predicting the initial size of home and street networks. Young people with a history of caregiver abuse have smaller home networks (emotional, ERR $=0.855, p<.05$ and instrumental, ERR $=0.831, p<.01)$, and larger instrumental street networks (ERR $=1.286, p<.05)$ compared with youth without a history of caregiver abuse. A similar pattern emerges for homeless youth with a history of conduct disorder and substance abuse. Youth with a history of conduct disorder and substance abuse have smaller instrumental home networks and larger instrumental street networks compared with youth without a conduct disorder or substance abuse, respectively. 
Table 3. Growth Curve Models of Street and Home Core Network Size for Emotional and Instrumental Ties $(\mathrm{N}=351)^{\mathrm{a}}$

\begin{tabular}{|c|c|c|c|c|}
\hline & \multicolumn{4}{|c|}{ Core Network Size by Relationship Origin } \\
\hline & \multicolumn{2}{|c|}{ Emotional } & \multicolumn{2}{|c|}{ Instrumental } \\
\hline & Street & Home & Street & Home \\
\hline Fixed effects & ERR & ERR & ERR & ERR \\
\hline Initial status & 0.607 & 1.673 & .607 & 1.462 \\
\hline Age & $1.208^{*}$ & 0.922 & 1.002 & $0.849^{* *}$ \\
\hline Gender (female $=1$ ) & 0.882 & 1.077 & 1.070 & 1.014 \\
\hline Sexuality (hetero $=1$ ) & 0.710 & 0.969 & 0.870 & 0.987 \\
\hline Caregiver abuse & 1.095 & $0.855^{*}$ & $1.286^{*}$ & $0.831^{* *}$ \\
\hline Major depression & 1.025 & 0.897 & 0.835 & 0.886 \\
\hline Conduct disorder & 0.870 & 0.962 & $1.525^{*}$ & $0.803^{*}$ \\
\hline Substance abuse & 1.131 & 0.941 & $1.516^{*}$ & 0.834 \\
\hline Growth rate & 1.000 & $0.993^{* * *}$ & $0.994^{*}$ & $0.993^{* * *}$ \\
\hline Age & 0.997 & $1.003^{*}$ & 1.002 & $1.004^{*}$ \\
\hline Gender $($ female $=1$ ) & 1.000 & 1.001 & 0.993 & 1.000 \\
\hline Sexuality $($ hetero $=1$ ) & 1.003 & 1.001 & 0.997 & 1.002 \\
\hline Caregiver abuse & 1.005 & $0.996^{*}$ & 0.999 & 0.998 \\
\hline Major depression & 1.005 & 1.003 & $1.011^{*}$ & 1.003 \\
\hline Conduct disorder & 1.002 & 0.996 & 0.994 & 1.000 \\
\hline Substance abuse & 1.001 & 1.002 & 0.994 & $1.007^{*}$ \\
\hline Random effects & $\mathrm{VC}$ & $\mathrm{VC}$ & $\mathrm{VC}$ & $\mathrm{VC}$ \\
\hline Initial status & $.813^{* * *}$ & $.515^{* * *}$ & $.769^{* * *}$ & $.536^{* * *}$ \\
\hline Level-1 error & .772 & .583 & .826 & 699 \\
\hline
\end{tabular}

$\mathrm{ERR}=$ event rate ratio; $\mathrm{VC}=$ variance component.

${ }^{*} p<.05 ;{ }^{* *} p<.01 ; * * * \quad p<.001$ (one-tailed test).

a. All variables are grand mean centered and models are estimated using and Overdispersed Poisson's error distribution.

These patterns suggest that homeless youth who are more cut off from their home connections for obtaining instrumental aid are likely to rely more heavily on street associates for instrumental aid. In contrast, lost emotional support connections from the home are not made up for with street connections.

How and why does the size of home versus street networks change the longer homeless youth remain on the street? With one exception, the overall decline in core network size reported earlier remains when investigating the size of home and street networks. The growth rates in the bottom part of Table 3 show that the longer young people remain homeless the smaller their emotional home networks and instrumental home or street networks will become. The one exception is that the size of emotional street networks remain unchanged over time $(E R R=1.000, n s)$. Emotional street connections are very few to begin with (on average less than one member) and smaller than other types of networks connection; thus, there are not many network members to lose. It is worth pointing out, however, that homeless youth do not increase their emotional street connections over time. In other words, homeless youth are not finding ways to develop emotional support from individuals they encounter on the street.

Variability in street and home network size trajectories are explained by four factors: caregiver abuse, substance abuse, major depression, and age. First, adolescents with a history of caretaker abuse lost emotional home ties at a steeper rate than adolescents without a history of abuse (ERR $=0.996, p<.05)$. Thus, youth with a history of caregiver abuse start out with fewer network members from their home environment and are more likely to lose home network members over time. Second, in contrast to homeless youth with a history of caregiver abuse, adolescents with a history of substance abuse experience less steep declines in their instrumental home ties compared with adolescents without a history of substance abuse (ERR $=1.007, p<.05)$. Maintaining instrumental home ties might be important for supplying the drugs/alcohol or for providing resources to purchase the drugs/alcohol to sustain their substance abuse. Third, depressed youth actually experience slight gains in their instrumental street ties the longer they remain homeless (ERR $=1.011, p<.05)$ compared with nondepressed youth. Finally, younger homeless youth experience less steep declines in their home networks (emotional or instrumental) compared with older homeless youth.

\section{Role Relationships}

This next phase of analysis investigates what type of relational tie connections (parents, other family member, friend, or partner) homeless youth are more likely to have and to maintain over time within their core networks for each type of relational tie. Thus, Table 4 reports the results from eight different models predicting the presence or absence of four different role relationships within emotional and instrumental networks.

Who is most likely to have and maintain ties to parents and other family members? When an adolescent first becomes homeless, about 33\% of them report having a parent within their core emotional network and $15 \%$ of them have a parent in their instrumental network. In other words, adolescents are more likely to report not having a parent in their core network. Female 
Table 4. Growth Curve Models of Network Role Relationships for Emotional and Instrumental Ties $(\mathrm{N}=351)^{\mathrm{a}}$

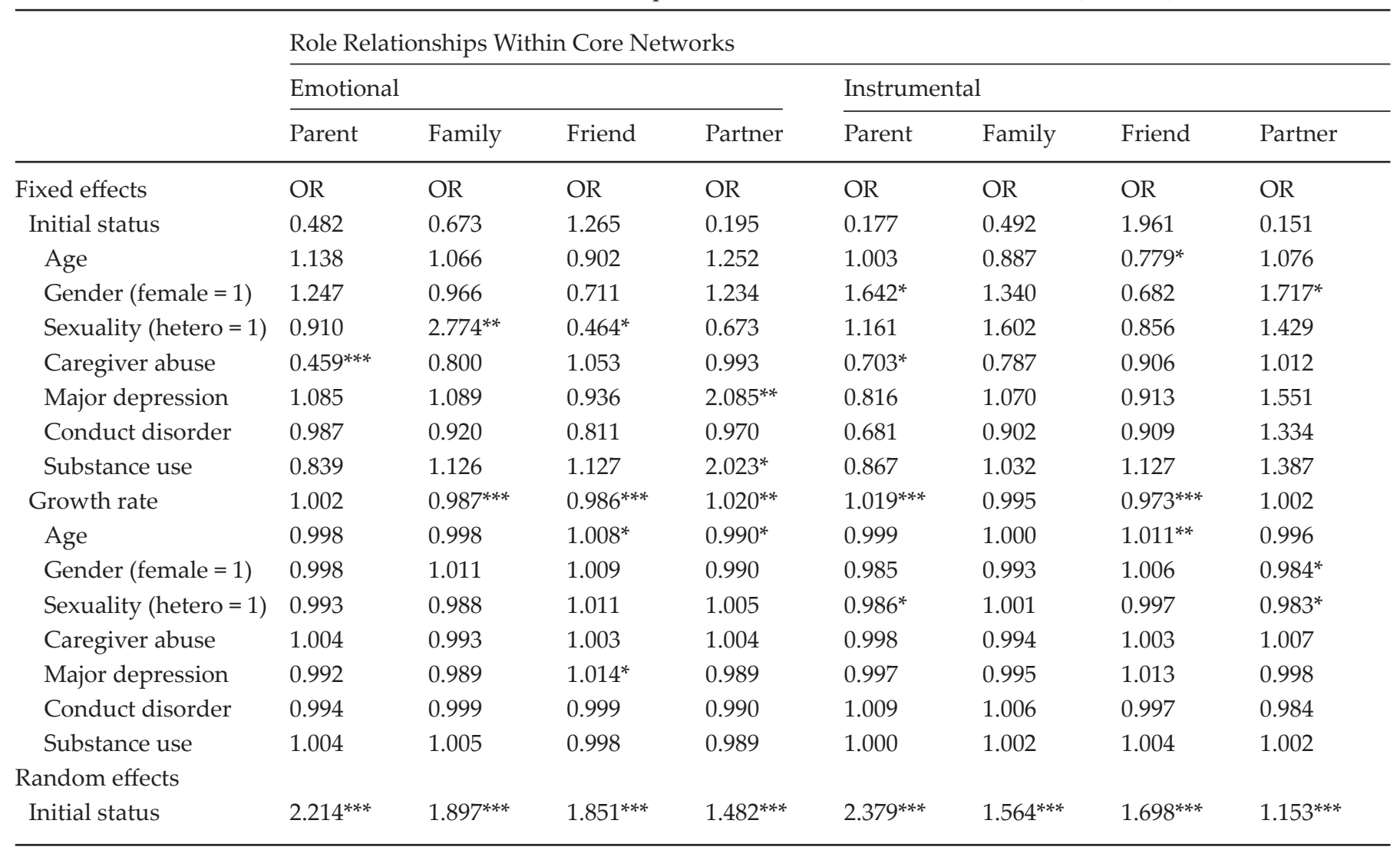

$\mathrm{OR}=$ odds ratio

${ }^{*} p<.05 ;^{* *} p<.01 ; * * *<<.001$ (one-tailed test)

a. All variables are grand mean centered and models are estimated using a Bernoulli error distribution.

homeless youth were more likely to report having a parent in their instrumental network than males (OR = $1.642, p<.05)$, whereas youth with a history of caregiver abuse were less likely to report having a parent in their emotional $(\mathrm{OR}=0.459, p<.001)$ or instrumental $(\mathrm{OR}=$ $0.703, p<.05)$ compared with youth without a history of conduct disorder. For youth with a history of caregiver abuse, then, having fewer home ties in their core networks at the onset of homelessness may stem from a lack of connection to their parents.

For most homeless young people, the odds of an adolescent reporting a parent within their instrumental network increased (OR $=1.019, p<.001)$ over time. After being homeless for 2 years, $22 \%$ of homeless youth report receiving instrumental support from a parent and $36 \%$ of homeless youth do so after 5 years on the street. Thus, there is a rapprochement between parents and offspring the longer the youth remains homeless. Nonheterosexual youth were especially likely to reconnect with their parents for instrumental aid $(\mathrm{OR}=.986$, $p<.05)$.
Similar to parents, homeless youth were less likely to report having a family member other than a parent within their emotional and instrumental networks. For example, at the onset of homelessness, $40 \%$ of youth report having a family member other than a parent providing emotional support. Heterosexual homeless youth were more likely to report having a family member other than a parent within their emotional network compared with nonheterosexual youth $(\mathrm{OR}=2.774$, $p<.01)$. It appears as though nonheterosexual youth are more cut off from their extended family. For all homeless youth, the probably of sustaining emotional support from other family members declines over time (OR $=0.987, p<.001)$. After 2 years of homelessness, the percentage receiving emotional support from other family members declines to $33 \%$ and $24 \%$ after 5 years of homelessness.

Who is most likely to have and maintain ties to friends and romantic partners? At the onset of homelessness, adolescents are more likely to have a friend in their 
emotional (56\%) and instrumental (66\%) networks than to report not having a friend. Heterosexual youth were less likely to report having a friend in their emotional networks compared with nonheterosexual youth $(\mathrm{OR}=$ $0.464, p<.01)$. Put another way, nonheterosexual youth were most likely to have a friend in their emotional network, possibly friendships with other nonheterosexual identified youth. In contrast to the rapprochement with parents, the odds of having a friend in core networks decline $(\mathrm{OR}=0.986, p<.001$ and $\mathrm{OR}=0.973, p<.001)$ the longer youth remain homeless. After 2 years of being homeless, $48 \%$ reported a friend in their emotional network and $50 \%$ reported a friend in their instrumental network. Declines in having a friend are not as steep for older adolescents $(\mathrm{OR}=1.008, p<.05$ and $\mathrm{OR}=1.011$, $p<.01)$ compared with younger, or homeless youth with a history of major depression within emotional networks $(\mathrm{OR}=1.014, p<.05)$ compared with youth without major depression.

Few homeless young people included a romantic partner in their emotional or instrumental networks at the onset of homelessness. For example, only $17 \%$ of homeless young people report having a romantic partner within their emotional networks. Adolescents with major depression $(\mathrm{OR}=2.085, p<.01)$ or with substance abuse problem $(\mathrm{OR}=2.023, p<.05)$ were more likely to report having a romantic partner in their emotional networks than adolescents without these mental health problems. Adolescent females were more likely to report having a romantic partner for instrumental aid than males $(\mathrm{OR}=1.717, p<.05)$. For all homeless young people, the odds of having a romantic partner for emotional support increase over time $(\mathrm{OR}=1.020, p<.01)$. After 2 years on the street, $24 \%$ report having a romantic partner in their emotional networks.

\section{DISCUSSION}

Consistent with the findings of Ennett et al. (1999), at the onset of homelessness the core networks of homeless youth were small: on average about two people. Nearly one-fifth of homeless youth had no one to turn to for help or aid and more than 1 in 10 felt there was no one who was concerned about them. The longer homeless youth remained on the street the smaller their networks became and the propensity for isolation increased. Homeless youth lost network members from both the home and the street. Overall, ties to home environments were more common than street ties, but parents often were not the source of the home connection. At the onset of homelessness, only 33\% of adolescents reported a parent in their emotional networks and 15\% reported parents in their instrumental networks. Over time, however, homeless youth increased their propensity of reporting a parent in their instrumental networks. Reestablishing relationships with parents in late adolescence or early adulthood is not unusual (Arnett, 2004) and this tendency appears to hold up among young people who have experienced homelessness.

Several characteristics of homeless youth were associated with the size and composition of their networks, and the changes over time. First, youth with conduct disorders tended to begin the study with small networks and their networks remained smaller over time as they lost network members at a constant rate. The pervasive negative impact of conduct disorder on network size was congruent with expectations and previous research showing conduct disordered adolescents have more difficulty maintaining relationships over time (for a review see Hinshaw \& Lee, 2003). Second, adolescents with a history of caregiver abuse also started out with smaller networks, but this was due to having fewer home connections. These youth are the least likely to report having a parent in their emotional network at the onset of homelessness. These youth also tended to lose home emotional ties at a significantly steeper rate compared with youth without caregiver abuse. Caregiver abuse is likely to produce more distance from parents and family and erode the parent - child relationship over time.

Third, depressed homeless young people started out with smaller networks, but they were better able to sustain their network connections over time, especially to street friends. Depressed young people were also more likely to report a significant other in their emotional networks compared with nondepressed homeless youth. Among homeless youth, depressed adolescents might be one of the "better" options for friendship and romantic relationships. In contrast to homeless youth with substance abuse problems or conduct disorder, depressed youth may appear less hostile and manipulative. Furthermore, depressed young people tend to cling to or create concern among their romantic partners and friends which may foster maintaining these associations (Hammen \& Rudolph, 2003). Fourth, substance abusers began the study with larger instrumental street networks and they were less likely to lose their instrumental home ties over time. Instrumental ties are likely to be very important for supplying or providing resources to purchase the drugs/alcohol necessary to sustain their habit. The general decline within instrumental street networks for all homeless youth may have prompted youth with a substance abuse problem to revert to their home environments. 
Although not the focus of this study, it is worth pointing out that nonheterosexual youth tended to have more friends in their emotional networks compared with heterosexual youth. These friendships may be with other nonheterosexual identified homeless youth. In other words, they may seek each other out for friendship. At the same time, nonheterosexual youth also were most likely to reconnect with their parents the longer they remained homeless. Nonheterosexual youth more often leave home due to parental rejection (Cochran et al., 2002; Whitbeck et al., 2004). Yet, their greater propensity to reconnect with parents could suggest that the sense of rejection may subside over time. Future research will have to explore this possibility.

Considered together, these findings support our theoretical premise that homeless young people often are deficient in the social skills necessary to form and maintain social relationships across time. By running away, these young people have taken an important and abrupt step in diminishing ties to family members, school, and others in the old neighborhood. This in itself serves to truncate social networks. Thus, our results are congruent with others who have found that the social networks of homeless adolescents are small (Ennett et al., 1999), and we extend these findings by showing that these already small networks tend to diminish with time (whether the network tie originates from home or the street) and in ways that vary according to an adolescent's history of caregiver abuse and mental health problems.

\section{Limitations}

The findings from this research should be considered in light of its limitations. Although these data provide important across-time information regarding the social networks of homeless young people, they rely solely on adolescents' self-reports. The absence of peer nominations and peer reports is an important limiting factor. We cannot be sure if the changes in network size are the result of actual changes in network size or simply the respondent's perception of changes taking place. A measure of perceived network size might be most consequential for depressed adolescents, who are likely to have distorted perceptions of their friendships (Brendgen et al., 2002). This could have affected the smaller network size of depressed youth when they first become homeless. The findings on differences in the growth rate across depressed homeless youth, however, are less likely to be biased due to self-reports. If depressed youth tend to perceive fewer friends, on average, then finding increases in street friends over time among depressed homeless youth is particularly compelling evidence. Finally, though we worked diligently to systematically sample, this is not a random sample. Younger adolescents were more easily recruited initially. We also caution against generalizing the results to all homeless adolescents, especially those in cities outside the Midwest.

\section{Conclusion and Future Directions}

Social networks may be a key point of intervention for homeless young people (Ennett et al., 1999; Johnson et al., 2005; Rice et al., 2008; Unger et al., 1998). As we learn more about the social networks of homeless young people we can consider how they may be potential sources of resiliency and a means of getting off the streets. Importantly, the findings from the current study research show that homeless youth are more likely to be connected to network members from their home environments than street associates. Prosocial networks made up of housed, school attending, or employed friends may provide emotional support and teach the social skills required for maintaining such support. Perhaps the most encouraging finding is that the breach with parents may not be permanent. Therefore, ties to parents can be protective for newly homeless adolescents (Rice et al., 2008) and provide windows of opportunity for longer term homeless.

A second hopeful note is the movement into partnered relationships. There is evidence that stable intimate relationships moderate antisocial behavior (Sampson, Laub, \& Wimer, 2006). Conversely, romantic alliances between substance abusers and antisocial young people may exacerbate such behaviors (Rutter, Quinton, \& Hill, 1990). We need further research to investigate the degree to which romantic attachments formed when homeless are protective. The less encouraging conclusion from the current research is that homeless youth are more likely to lose their sources of instrumental aid and emotional support the longer they remain homeless. Some homeless youth are more disadvantaged in this regard than others. Loss of emotional home ties is most prevalent among youth with a history of caregiver abuse and homeless youth who suffer from a conduct disorder have persistently smaller networks.

\section{REFERENCES}

American Psychiatric Association (2000). Diagnostic and statistical manual of mental disorders (4th ed., text rev.). Washington, DC: APA. 
Arnett, J. (2004). Emerging adulthood. Oxford, UK: Oxford University Press.

Bao, W., Whitbeck, L., \& Hoyt, D. (2000). Life stressors, social support networks, and depressive symptoms among homeless and runaway adolescents. Journal of Health and Social Behavior, 41, $408-420$.

Berndt, T., \& Hanna, N. (1995). Intimacy and self disclosure in friendships. In K. J. Rotenberg (Ed.), Disclosure processes in children and adolescents (pp. 57 - 77). New York, NY: Cambridge University Press.

Brendgen, M., Vitaro, F., Turgeon, L., \& Poulin, F. (2002). Reactively and proactively aggressive children: Antecedent and subsequent characteristics. Journal of Child Psychology and Psychiatry and Allied Disciplines, 43, 495 - 505.

Buhrmester, D., \& Prager, K. (1995). Patterns and functions of self-disclosure during childhood and adolescence. In K. J. Rotenberg (Ed.), Disclosure processes in children and adolescents (pp. 10 - 56). New York, NY: Cambridge University Press.

Burt, M. (1996). Practical methods for counting homeless people: A manual for state and local jurisdictions (2nd ed.). Washington, D.C.: Urban Institute.

Cochran, B., Stewart, A., Ginzler, J., \& Cauce, A. (2002). Challenges faced by homeless sexual minorities: Comparison of gay, lesbian, bisexual, and transgendered homeless adolescents with their heterosexual counterparts. American Journal of Public Health, 92, 773 - 777.

Cotterell, J. (2007). Social networks in youth and adolescence. New York, NY: Routledge.

Dennis, M., Iachan, R., Thornberry, J., \& Bray, R. (1991). The RTI method: Sampling over time. In C. M. Taeuber (Ed.), Enumerating homeless persons' methods and data needs (pp. 167 -170). Washington, DC: Bureau of the Census, U.S. Department of Commerce.

Department of Health and Human Services (2001). Protection of Human Subjects, Code of Federal Regulations, Title 45, Public Welfare. Washington, DC: Department of Health and Human Services National Institutes of Health, Office of Protection from Research Risks, Part 46. Revised November 13, 2001.

Du Rocher Schudlich, T., Shamir, H., \& Cummings, E. (2004). Representations of family relations as a mediator between marital conflict and children's adjustment. Social Development, 13, $171-192$.

Ennett, S., Bailey, S., \& Federman, E. (1999). Social network characteristics associated with risky behaviors among runaway and homeless youth. Journal of Health $\mathcal{E}$ Social Behavior, 40, $63-78$.

Ennew, J. (1994). Street and working children: A guide to planning. London, UK: Save the Children.

Hagen, J., \& McCarthy, B. (1997). Mean streets: Youth crime and homelessness. New York, NY: Cambridge University Press.
Hammen, C., \& Rudolph, K. (2003). Childhood depression. In E. J. Mash \& R. A. Barkley (Eds.), Child psychopathology (2nd ed., pp. 233 - 278). New York, NY: Guilford Press.

Hinshaw, S., \& Lee, S. (2003). Conduct and oppositional defiant disorders. In E. J. Mash \& R. A. Barkley (Eds.), Child psychopathology (2nd ed., pp. 144 - 198). New York, NY: Guilford Press.

Hox, J. (2002). Multilevel analysis: Techniques and applications. Mahwah, NJ: Lawrence Erlbaum Associates.

Iachan, R. (1989). Sampling in time and space. Proceedings of the survey research methods section, American Statistical Association, 636 - 640. Retrieved from http://www.amastat. org/sections/srms/Proceedings/papers/allyearsf/1989 116. pdf

Jensen, P., Roper, M., Fisher, P., Piacentini, J., Canino, G., Richters, J., et al. (1995). Test-retest reliability of the Diagnostic Interview Schedule for Children (DISC. 2.1). Archives of General Psychiatry, 52, $67-71$.

Johnson, K., Whitbeck, L., \& Hoyt, D. (2005). Predictors of social network composition among homeless and runaway adolescents. Journal of Adolescence, 28, 231 - 248.

Koegel, P., Burnam, M., \& Morton, J. (1996). Enumerating homeless people: Alternative strategies and their consequences. Evaluation Review, 20, 378 - 403.

Link, B., Cullen, F., Struening, E., Shrout, P., \& Dohrenwend, B. 1989. A modified labeling theory approach to mental disorders: An empirical assessment. American Sociological Review, 54, $400-423$.

McCrady, B. (2006). Family and other close relationships. In W. Miller \& K. Carroll (Eds.), Rethinking substance abuse (pp. 166 - 181). New York, NY: Guildford Press.

Newcomb, A., \& Bagwell, C. (1995). Children's friendship relations: A meta-analysis. Psychological Bulletin, 117, 306 - 347.

Parker, J., Rubin, K., Erath, S., Wojslawowicz, J., \& Buskirk, A. (2006). Peer relationships, child development, and adjustment: A developmental psychopathology perspective. In D. Cicchetti \& D. J. Cohen (Eds.), Developmental psychopathology (pp. 419 - 493). Hoboken, NJ: Wiley.

Patterson, G. (1982). Coercive family process. Eugene, OR: Castalia.

Phelan, J., \& Link, B. (1999). Who are "the homeless"? Reconsidering the stability and composition of the homeless population. American Journal of Public Health, 89, 1334 - 1338.

Raudenbush, S., \& Bryk, A. (2002). Hierarchical linear models: Applications and data analysis methods. Thousand Oaks, CA: Sage Publications.

Rice, E., Milburn, N., \& Rotheram-Borus, M. (2007). Pro-social and problematic social network influences on HIV/AIDS risk behaviors among newly homeless youth in Los Angeles. AIDS Care, 19, $697-704$.

Rice, E., Stein, J., \& Milburn, N. (2008). Drug use among homeless young people in Los Angeles and Melbourne. The Journal of Adolescent Health, 43, $296-305$. 
Rutter, M., Quinton, D., \& Hill, J. (1990). Adult outcome of institution-reared children: Males and females compared. In L. Robbins \& M. Rutter (Eds.), Straight and deviant pathways from childhood to adulthood (pp. 135 - 157). Cambridge, UK: Cambridge University Press.

Sampson, R., Laub, J., \& Wimer, C. (2006). Does marriage reduce crime? A counterfactual approach to within individual causal effects. Criminology, 44, 465 - 507.

Schwab-Stone, M., Fisher, P., Piacentini, J., Shaffer, D., Davies, M., \& Briggs, M. (1993). The diagnostic interview schedule for children - revised version (DISC - R). Test-retest reliability. Journal of the American Academy of Child E Adolescent Psychiatry, 32, 651 - 657.

Shaffer, D., Schwab-Stone, M., Fisher, P., Cohen, P., Piacentini, J., Davies, M., et al. (1993). The diagnostic interview schedule for children - revised version (DISCR). Preparation, field testing, interrater reliability, and acceptability. Journal of the American Academy of Child E Adolescent Psychiatry, 32, 643-650.

Snijders, T., \& Bosker, R. (1999). Multilevel analysis: An introduction to basic and advanced multilevel modeling. London, U.K.: Sage Publishers.

South, S., \& Haynie, D. (2004). Friendship networks of mobile adolescents. Social Forces, 83, $315-350$.

Tavecchio, L., \& Thomeer, M. (1999). Attachment, social network, and homelessness in young people. Social Behavior and Personality, 27, $247-262$.
Unger, J., Kipke, M., Simon, T., Johnson, C., Montgomery, S., \& Iverson, E. (1998). Stress, coping, and social support among homeless youth. Journal of Adolescent Research, 13, 134 - 157.

Van Der Ploeg, J., Gaemers, J., \& Hoogendam, P. (1991). Homeless youth. Leiden, The Netherlands: DSWO Press.

Weinstein, S., Noam, G., Grimes, K., Stone, K., \& SchwabStone, M. (1990). Convergence of DSM-III diagnoses and self-reported symptoms in child and adolescent inpatients. Journal of the American Academy of Child E Adolescent Psychiatry, 29, $627-634$.

Whitbeck, L. (2009). Mental health and emerging adulthood among homeless young people. New York, NY: Psychology Press.

Whitbeck, L., Chen, X., Hoyt, D., Tyler, K., \& Johnson, K. (2004). Mental disorder, subsistence strategies, and victimization among gay, lesbian, and bisexual homeless and runaway adolescents. Journal of Sex Research, 41, 329 - 342.

Whitbeck, L., \& Hoyt, D. (1999). Nowhere to grow: Homeless and runaway adolescents and their families. New York, NY: Aldine de Gruyter.

Whitbeck, L., Johnson, K., Hoyt, D., \& Cauce, A. (2004). Mental disorder and comorbidity among runaway and homeless adolescents. Journal of Adolescent Health, 35, 132 - 140.

Wilson, B., \& Gottman, J. (2002). Marital conflict, repair and parenting. In M. H. Bornstein (Ed.), Handbook of parenting: Social conditions and applied parenting (Vol. 4, pp. 227 - 258). Hillsdale, NJ: Lawrence Erlbaum Publishing. 